\title{
Erratum to: Case Report: High Chromium and Cobalt Levels in a Pregnant Patient with Bilateral Metal-on-Metal Hip Arthroplasties
}

Juliane Fritzsche PhD, Cornelia Borisch MD,

Christof Schaefer MD, PhD

Published online: 14 July 2012

(C) The Association of Bone and Joint Surgeons (B) 2012

\section{Erratum to: Clin Orthop Relat Res \\ DOI 10.1007/s11999-012-2398-0}

In our article, High Chromium and Cobalt Levels in a Pregnant Patient with Bilateral Metal-on-Metal Hip Arthroplasties published online June 13, 2012, the patient described in the case report did not receive bilateral Birmingham Hip Resurfacing (BHR) implants (Smith \& Nephew, Inc, Memphis, TN, USA). This erroneous statement was made throughout the article including in the figure legends and as the last point in Table 3. In the operative report of the first revision surgery that was available to us, the preexisting prostheses were mentioned to be McMinn prostheses leading us to the assumption that BHR implants were used. The orthopaedic surgeon who currently cares for the patient informed us that instead, Conserve ${ }^{\circledR}$ Plus Total Resurfacing Implants (Wright Medical Technology, Inc, Arlington, TN, USA) were implanted. We regret this error.

The online version of the original article can be found under doi:10.1007/s11999-012-2398-0.

J. Fritzsche, C. Borisch ( $₫)$, C. Schaefer Pharmakovigilanz- und Beratungszentrum für Embryonaltoxikologie (Institute for Clinical Teratology and Drug Risk Assessment in Pregnancy),

Institut für Klinische Pharmakologie und Toxikologie,

Charité Universitätsmedizin Berlin, Spandauer Damm 130,

Haus 10, D-14050 Berlin, Germany

e-mail: cornelia_borisch@web.de 